\title{
Absorção de imunoglobulinas G (IgG) do colostro pelo bezerro recém-nascido e suas concentrações na glândula mamária
}

\author{
Absorption of immunoglobulins G (IgG) from colostrum by newborn \\ calves and the concentrations of IgG in different parts \\ of the mammary gland
}

\author{
Cristiano Pereira Barbosa, ${ }^{\star}$ Edmundo Benedetti, ${ }^{\star \star}$ Deise Aparecida de Oliveira Silva, ${ }^{\star \star \star}$ Ernesto Akio Taketomi, ${ }^{, \star \star \star}$
} Ednaldo Carvalho Guimarães ${ }^{\star \star \star \star \star}$

\begin{abstract}
Resumo
Foram estudados neste trabalho, a capacidade de absorção de IgG pelo bezerro lactente nas primeiras 24 horas de vida e possíveis diferenças de concentrações de IgG entre o colostro antes do bezerro mamar, que está localizado no seio lactífero parte glandular e o colostro depois da mamada e ligeira esgota, que está localizado nos ductos lactíferos. Para isso, foi analisado o colostro de 15 vacas recém-paridas e o soro sangüíneo dos bezerros filhos dessas vacas, em duas colheitas, uma antes da primeira mamada, logo após o nascimento, e outra 24 horas depois da primeira. O teste de ELISA foi utilizado para detecção e quantificação da IgG, tanto no colostro, quanto no soro sangüíneo. Os resultados mostraram que houve grande absorção de IgG pelo bezerro recém-nascido $(p<0,05)$, em 24 horas, mas não houve diferença de concentração $(p>0,05)$ entre o colostro proveniente do seio lactífero (parte glandular) e dos ductos lactíferos.
\end{abstract}

Palavras-chave: imunoglobulina, colostro, glândula mamária, bezerro, bovino de leite.

\begin{abstract}
The present study examined the capacity of $\lg G$ absorption by calves during the first 24 hours and possible different $\lg G$ concentrations in colostrum from two different parts of the mammary gland, the sinus lactifer pars glandularis and the ductus lactiferi. The colostrum from 15 newly-delivered cows and the serum from their calves, obtained before the first suckling and after 24 hours, were examined. An ELISA test was developed for the detection and quantification of IgG in colostrum and IgG in the serum. The results showed a high absorption $(p<0,05)$ of IgG by newborn calves in the first 24 hours, and there was no difference in the concentration $(p>0,05)$ of colostrum in the two parts of the mammary gland.
\end{abstract}

Keywords: immunoglobulin, colostrum, mammary gland, calf, dairy cattle.

\section{Introdução}

O colostro é a primeira secreção mamária produzida após o parto. É de importância primordial para o filhote, altamente nutritivo e, em algumas espécies, possui componentes essenciais para a sobrevivência no período neonatal (Jacobson e McGilliard, 1988).

A absorção de proteína intacta pelo intestino do recém-nascido representa uma forma de transferência de anticorpos, caracterizada como imunidade passiva. Nos bovinos, como em algumas outras espécies, a transferência de gamaglobulinas, que são as imunoglobulinas $(\mathrm{Ig})$, se faz após o nascimento, via colostro materno, já que via placenta ela não ocorre. A imunoglobulina do tipo $\mathrm{G}$ (IgG) é a mais importante e deve ser ingerida rapidamente após o nascimento, pois a mucosa intestinal é altamente permeável a macromoléculas apenas por um curto periodo, fechando-se posteriormente, para evitar a passagem de proteínas complexas (Argenzio, 1988 e McGuirk, 1999).

A maior transferência seletiva de IgG do sangue para a secreção glandular no pré-parto aumenta a concentração de IgG no colostro antes do parto que, além de proteger a glândula mamária, susceptível à entrada de patógenos com o início da lactação, tem a função de transferência passiva de IgG para o bezerro recém-nascido já na primeira mamada (Panchal et al., 1998).

\footnotetext{
* Mestrando em Ciências Veterinárias - Clínica e Cirurgia da Faculdade de Medicina Veterinária - UFU. Autor para correspondência: Av. Rio Branco, 567. Centro. 38400-056. Uberlândia, MG. Fone: (34)3234-2316.

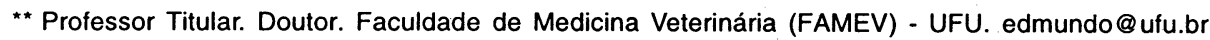

${ }^{\star \star \star}$ Médica-veterinária do Laboratório de Imunologia. NUIMP/UFU.

****Professor Titular. Doutor. Laboratório de Imunologia. NUIMP/UFU.

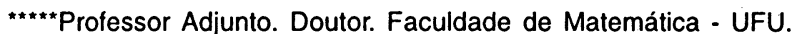


A alta temperatura ambiental pode influenciar na composição do colostro e imunização passiva do bezerro. Segundo Lacetera (1998), vacas expostas a alta temperatura ambiental no final da gestação e início da lactação sofrem redução de imunoglobulinas no colostro. Os bezerros nascidos neste ambiente de calor têm a absorção de imunoglobulinas prejudicada, tanto devido à menor ingestão de colostro quanto pela baixa qualidade do colostro de suas mães, proporcionandoIhes niveis mais baixos de IgG plasmática por até 36 horas após o nascimento.

Sultan et al. (1993) verificaram que as concentrações de imunoglobulinas no colostro diminuem em torno de $70 \%$ do primeiro para o segundo dia pós-parto, enquanto se mantêm alta no soro sangüíneo do bezerro que $o$ ingeriu durante os três primeiros dias de idade.

Segundo Rajaraman et al. (1997), a aquisição de imunidade passiva é indicada pelas concentrações de IgG no soro. Os leucócitos mononucleares do sangue dos bezerros são funcionalmente hiporresponsivos e de composição diferente dos leucócitos de vacas adultas não prenhes. Estas diferenças refletem a imaturidade do sistema imune do neonato, contribuindo para o aumento da susceptibilidade às doenças infecciosas.

A concentração de IgG plasmática e a atividade da gamaglutamil-transferase (GGT) aumentam após a ingestão de colostro, mas somente a IgG permanece elevada, sendo o melhor indicador de ingestão de colostro até o sétimo dia de vida do bezerro (Hadorn e Blum, 1997). Pode-se verificar ainda que a IgG colostral absorvida e circulante no soro sangüíneo chega ao trato intestinal onde realiza um papel de imunidade entérica local, principalmente a infecções virais entéricas não-invasivas (McGuirk, 1999).

Segundo Virtala et al. (1999), bezerros com baixos níveis de IgG séricos, devido a falha de transferência passiva de anticorpos, tiveram duas vezes mais casos de pneumonias do que os bezerros com maiores concentrações de IgG, assim como bezerros com inadequada concentração de IgG e de proteína plasmática até 24 horas de vida correm maiores riscos de mortalidade e morbidade respiratória das primeiras semanas até antes do desmame. Este estado de imunidade passiva está associado com o desenvolvimento do bezerro antes e após a desmama (Wittum e Perino, 1995).

$O$ objetivo deste estudo foi verificar a absorção de lgG pelo bezerro recém-nascido 24 horas após a ingestão de colostro materno e a possível diferença na concentração de IgG entre o colostro localizado no seio lactífero glandular e nos ductos galactóferos.

\section{Material e métodos}

\section{Animais e amostras de soro e colostro}

Foram utilizadas 15 vacas mestiças leiteiras, recém-paridas, de idades entre 3 e 8 anos, de três rebanhos diferentes, no município de Uberlândia, MG, para a colheita de colostro de todas as tetas funcionais. Foram utilizados 15 bezerros, sendo nove machos e seis fêmeas, recém-nascidos das referidas vacas e de mesma raça, para a colheita de sangue. As amostras foram obtidas entre os meses de março e agosto de 2001.
O colostro das vacas foi ordenhado logo após o parto antes da mamada do bezerro (colostro-pré), retirando-se de cada teta os primeiros cinco jatos e reunidos em apenas um frasco. Em seguida colocava-se o bezerro recém-nascido para mamar, realizava-se uma pequena esgota e colhia-se novamente o colostro da mesma forma que a primeira (colostropós).

As amostras de colostro-pré foram consideradas como sendo o colostro contido no seio lactífero parte glandular e seio lactífero parte papilar, enquanto as de colostro-pós foram consideradas como o colostro contido nos ductos lactíferos. A nomenclatura anatômica utilizada está de acordo com o International Committee on Veterinary Gross Anatomical Nomenclature (1994).

Foram colhidos em torno de $10 \mathrm{ml}$ de sangue dos bezerros por venopunção jugular antes da primeira mamada (soropré) e 24 horas após esta primeira mamada (soro-pós).

Logo após a colheita, todas as amostras de sangue e colostro foram levadas para o laboratório de Imunologia, da Universidade Federal de Uberlândia e imediatamente processadas. O colostro inicialmente foi centrifugado (centrífuga EPPENDORF 5804 R) a 4.500 r.p.m. por 45 minutos a $4^{\circ} \mathrm{C}$ e, em seguida, a gordura superficial e o precipitado foram desprezados e o sobrenadante foi filtrado e novamente centrifugado, sendo então aliquotado e estocado a $-20^{\circ} \mathrm{C}$, até ser analisado para a dosagem de IgG. As amostras de sangue foram centrifugadas (centrífuga EXCELSA 2, modelo 205 N) a 3.000 r.p.m. por 15 minutos e o soro obtido foi aliquotado e estocado a $-20^{\circ} \mathrm{C}$ para análise da dosagem de IgG.

\section{ELISA para deteç̧ão de IgG bovina}

A detecção de IgG bovina foi realizada através do teste ELISA (enzyme-linked immunosorbent assay), como descrito por Silva et al. (1997), com modificações.

Placas de microtitulação (Costar, Sigma Chemical Co., USA) foram sensibilizadas com IgG de cobaio anti-IgG bovina na concentração de $10 \mu \mathrm{g} / \mathrm{ml}$ em tampão carbonato-bicarbonato a $0,06 \mathrm{M}, \mathrm{pH}=9,6$ durante uma noite a $4^{\circ} \mathrm{C}$. Em seguida, as placas foram lavadas por três vezes com solução salina tamponada com fosfatos $0,01 \mathrm{M}, \mathrm{pH}=7,2$ (PBS) contendo Tween 20 a $0,05 \%$ (PBS-T). Subseqüentemente, as placas foram bloqueadas com PBS-T adicionado de soro eqüino normal a $5 \%$ (PBS-TE) durante 30 minutos a $37^{\circ} \mathrm{C}$. Após lavagens com PBS-T, as placas foram incubadas com amostras de soros (1:10 e 1:100) e colostro (1:100 e 1:1000) em duplicata, diluídas em PBS-TE, e incubadas por 45 minutos a $37^{\circ} \mathrm{C}$. Em seguida, as placas foram novamente lavadas com PBS-T por seis vezes e incubadas com o conjugado anti-IgG bovinaperoxidase (preparado conforme descrito por Wilson e Nakane, 1978) diluído a 1:500 em PBS-TE durante 45 minutos a $37^{\circ} \mathrm{C}$. Após novas lavagens com PBS-T, a reação foi desenvolvida pela adição do substrato enzimático, consistindo de ABTS (2,2'-azino-bis-3-ethyl-benzthiazoline sulfonic acid; Sigma) a $0,01 \mathrm{M}$ em tampão citrato-fosfato a $0,07 \mathrm{M}(\mathrm{pH} 4,2)$ contendo $0,03 \%$ de $\mathrm{H}_{2} \mathrm{O}_{2}$. A leitura foi realizada a $405 \mathrm{~nm}$ em leitor de microplacas (Titertek Multiskan Plus MK II, Flow Laboratories, USA). Os resultados foram expressos em $\mathrm{mg} / \mathrm{ml}$ de $\mathrm{lgG}$, comparando-se com uma curva controle de IgG bovina, incluída em cada placa. 


\section{Análises estatísticas}

As análises estatísticas foram feitas utilizando-se análise descritiva, intervalo de confiança para média aritmética e o teste $\mathrm{t}$ de Student com amostras pareadas, a nível de significância de 5\%, conforme Vieira (1998).

\section{Resultados}

Do total de 30 amostras de colostro, colhidas de 15 vacas recém-paridas, foram analisadas as amostras de colostro antes (colostro-pré) e depois da mamada e esgota (colostropós), onde se observou uma grande variação de animal para animal, em termos de concentração de IgG e porcentagens de acréscimo ou decréscimo (Tabela 1).

Tabela 1: Concentração de Imunoglobulinas G ( $\lg G)$ no colostro antes (pré) e após (pós) a mamada pelo bezerro e suas respectivas porcentagens de decréscimo ou acréscimo.

\begin{tabular}{crrr}
\hline $\begin{array}{c}\text { Número da } \\
\text { amostra }\end{array}$ & $\begin{array}{r}\text { Colostro-pré } \\
(\mathrm{mg} / \mathrm{ml})\end{array}$ & $\begin{array}{r}\text { Colostro-pós } \\
(\mathrm{mg} / \mathrm{ml})\end{array}$ & $\begin{array}{r}\text { Decréscimo(D) ou } \\
\text { Acréscimo(A) }\end{array}$ \\
\hline 1 & 52,7 & 25,3 & 52,0 (D) \\
2 & 6,3 & 6,7 & $6,3(\mathrm{~A})$ \\
3 & 22,8 & 25,2 & 10,5 (A) \\
4 & 12,8 & 4,7 & $63,3(\mathrm{D})$ \\
5 & 74,4 & 17,9 & 75,9 (D) \\
6 & 33,0 & 13,9 & 57,9 (D) \\
7 & 180,5 & 95,7 & 47,0 (D) \\
8 & 10,6 & 3,3 & 68,9 (D) \\
9 & 61,3 & 98,8 & $61,2(\mathrm{~A})$ \\
10 & 28,7 & 49,9 & 73,9 (A) \\
11 & 22,0 & 16,5 & 25,0 (D) \\
12 & 31,7 & 45,7 & 44,2 (A) \\
13 & 265,0 & 132,7 & 49,9 (D) \\
14 & 24,0 & 12,7 & 47,1 (D) \\
15 & 24,8 & 29,9 & 17,7 (A) \\
\hline
\end{tabular}

Quando comparado o colostro-pré e pós, dos 15 pares de amostras, nove $(60 \%)$ apresentaram um decréscimo na concentração de lgG, variando de $25,0 \%$ a $75,9 \%$, com média de decréscimo de $54,1 \%$, enquanto em outros seis pares de amostras (40\%) foi observado um acréscimo variando de $6,3 \%$ a $73,9 \%$, com média de acréscimo de $35,6 \%$.

A média aritmética das amostras de colostro-pré foi de 56,7 $\mathrm{mg} / \mathrm{ml}$ de $\mathrm{lgG}$, com intervalo de confiança de $95 \%$ para esta média, apresentando limite inferior e limite superior de 17,0 $\mathrm{mg} / \mathrm{ml} \mathrm{e} 96,4 \mathrm{mg} / \mathrm{ml}$, respectivamente. Devido à grande variabilidade dos dados, cujo coeficiente de variação (CV) foi de $126,5 \%$, a média geométrica foi a medida de posição que melhor representou a variável, e neste caso, seu valor foi de $33,9 \mathrm{mg} / \mathrm{ml}$ de lgG.

Para as amostras de colostro-pós, a média aritmética foi de $38,5 \mathrm{mg} / \mathrm{ml}$ de $\mathrm{lgG}$, com intervalo de confiança de $95 \%$ (16,6 a
$60,5 \mathrm{mg} / \mathrm{ml}$ ). O coeficiente de variação (CV), neste caso, foi de $102,8 \%$ e a média geométrica foi de $23,1 \mathrm{mg} / \mathrm{ml}$ de $\mathrm{lgG}$.

Ao se compararem as médias obtidas do colostro-pré e pós, utilizando-se o teste $t$ de Student, observou-se que não houve diferença estatisticamente significativa $(p>0,05)$, entre as concentrações de IgG (Figura 1).

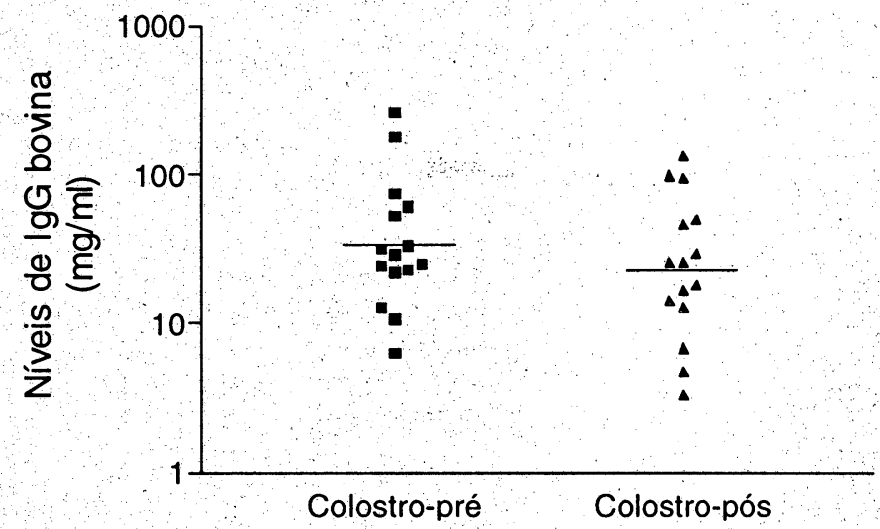

Figura 1: Comparação entre os níveis de Imunoglobulinas $G$ (IgG) obtidas do colostro antes (pré) e após (pós) a mamada pelos bezerros $(n=15)$. As barras horizontais representam a média geométrica obtida para cada grupo.

Do total de 30 amostras de soro sangüíneo; obtidas de 15 bezerros, foi avaliada a absorção de IgG após um período de 24 horas.

Um dos bezerros não conseguiu mamar em 24 horas, devido à hipocalcemia pós-parto e prolapso de útero apresentados pela mãe; então, foi descartado do trabalho, ficando apenas 14 bezerros e 28 amostras de sangue. $A$ vaca, no entanto, teve o colostro colhido antes de se debilitar, realizando-se somente a esgota manual para as duas amostras de colostro, sendo então incluída no estudo.

Analisando-se as amostras de soro antes da mamada (soropré) e de 24 horas depois (soro-pós), observaram-se variações, com aumento na concentração de $\lg \mathrm{g}$ em praticamente todas as amostras de soro-pós (Tabela 2). Somente uma, das 14 amostras pareadas de soro, não apresentou variação, enquanto as demais variaram, nos níveis de IgG, de 33,3\% a $31.900 \%$, com média de $4.670 \%$.

As amostras de soro-pré apresentaram média aritmética de $0,8 \mathrm{mg} / \mathrm{ml}$ com intervalo de confiança de $95 \%$ e com os limites inferior e superior variando de 0,2 a $1,4 \mathrm{mg} / \mathrm{ml}$. A média geométrica foi de $0,3 \mathrm{mg} / \mathrm{ml}$ com um coeficiente de variação (CV) de $128,6 \%$.

Em relação às amostras de soro-pós, a média aritmética apresentada foi de $6,9 \mathrm{mg} / \mathrm{ml}$; com intervalo de confiança de $95 \%(1,8$ a $12,1 \mathrm{mg} / \mathrm{ml})$. O coeficiente de variação foi de $128,7 \%$, apresentando uma média geométrica de $3,9 \mathrm{mg} / \mathrm{ml}$.

Ao se comparar as médias dos soros pré e pós, utilizando-se o teste $\mathrm{t}$ de Student, observou-se estatisticamente que há diferença entre as variáveis a nível de significância de $5 \%$ $(p<0,05)$, que indica um aumento significativo na concentração de IgG no soro do bezerro, em 24 horas após a primeira mamada (Figura 2). 
Tabela 2: Concentração de Imunoglobulinas G (IgG) no soro de bezerros antes (pré) e 24 horas após (pós) a mamada e suas respectivas porcentagens de acréscimo.

\begin{tabular}{crrr}
\hline $\begin{array}{c}\text { Número da } \\
\text { amostra }\end{array}$ & $\begin{array}{r}\text { Soro-pré } \\
(\mathrm{mg} / \mathrm{ml})\end{array}$ & $\begin{array}{r}\text { Soro-pós } \\
(\mathrm{mg} / \mathrm{ml})\end{array}$ & $\begin{array}{r}\text { Acréscimo } \\
\%\end{array}$ \\
\hline 1 & 2,7 & 5,8 & 114,8 \\
2 & 1,8 & 2,4 & 33,3 \\
3 & 0,01 & 3,2 & $31.900,0$ \\
4 & 0,4 & 0,9 & 125,0 \\
5 & 3,2 & 5,0 & 56,2 \\
6 & 0,2 & 1,9 & 850,0 \\
7 & 0,2 & 6,6 & $3.200,0$ \\
8 & 0,3 & 34,3 & $11.333,3$ \\
9 & 0,2 & 16,0 & $7.900,0$ \\
10 & 0,4 & 1,2 & 200,0 \\
11 & 0,6 & 4,3 & 616,7 \\
12 & 0,2 & 11,3 & $5.550,0$ \\
13 & 0,1 & 3,6 & $3.500,0$ \\
14 & 0,8 & 0,8 & 0,0 \\
\hline
\end{tabular}

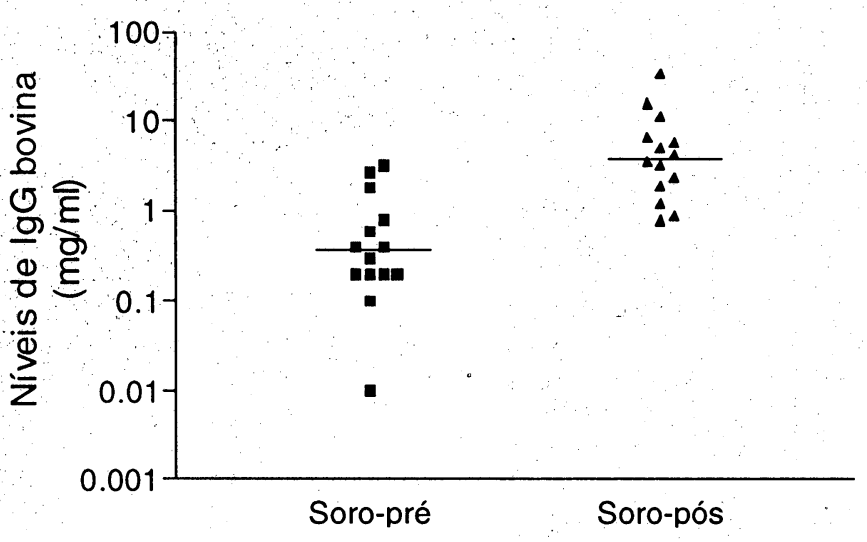

Figura 2: Comparação entre os níveis de Imunoglobulinas $\mathrm{G}$ (IgG) do soro de bezerros antes (pré) e 24 horas após (pós) a mamada $(n=14)$. As barras horizontais representam a média geométrica obtida para cada grupo.

\section{Discussão}

A determinação de valores de concentração de $\lg G$, tanto no colostro quanto no soro, é influenciada por uma série de fatores que resultam em diferenças entre diversos autores. Estas diferenças ocorrem, principalmente, devido às técnicas utilizadas na detecção de IgG, que variaram nos diversos trabalhos consultados. Dentro das mesmas técnicas, pode haver antígenos e reagentes de maior ou menor sensibilidade que outros, além das próprias expressões de unidades serem registradas de modo diferente.

No entanto, o importante ao se discutir o trabalho com outros autores, neste caso, é a verificação de variações na concen- tração de IgG, nas duas amostras de cada material, colostro da vaca e soro sangüíneo do bezerro.

Feitosa et al. (2001) verificaram uma enorme discordância de opiniões entre os vários autores, quanto à definição de um valor ideal da concentração de imunoglobulinas no soro sangüíneo de bezerros recém-nascidos, que thes conferisse uma adequada imunidade passiva.

Com relação às concentrações séricas de $\mathrm{IgG}$ em bezerros com 24 horas de vida, a média encontrada neste trabalho, de $6,9 \mathrm{mg} / \mathrm{ml}$ em bezerros com transferência de imunidade passiva, difere de outros trabalhos; assim como também aqueles verificados por Feitosa et al. (2001), ao compararem seus resultados com outros autores, onde são semelhantes com alguns dados e diferem de outros quanto aos valores mínimos de IgG para transferência de imunidade. Isto evidencia, possivelmente, a natureza química do colostro, além da própria individualidade da cria.

A concentração de IgG sérica teve um aumento significativo $(p<0,05)$, quando comparadas as amostras de soro dos bezerros logo após o nascimento e com 24 horas de vida, quando já havia ingerido o colostro. Este aumento chegou à média de $4.670 \%$, que muito se assemelha ao aumento médio de mais de $2.100 \%$ verificado por Quigley III et al. (1998). Outros autores como Erhard et al. (1999a) verificaram também um aumento médio de $3.666,5 \%$ nas concentrações de $\operatorname{lgG}$ sérica, em apenas 12 horas após a primeira mamada de colostro materno.

Já Erhard et al. (1997) e Romdhane et al. (1997) observaram que as maiores médias de concentrações séricas de $\mathrm{lgG}$ dos bezerros neonatos ocorreram com 24 horas de vida. Estes últimos autores observaram também um expressivo aumento em porcentagem de $\mathrm{lgG}$, em torno de $12.000 \% \mathrm{em}$ média, quando comparadas às duas amostras de soro, antes da mamada e após a mamada, com um dia de idade. Rajaraman et al. (1997) verificaram um aumento em torno de $10.000 \%$, enquanto Hopkins e Quigley III (1997) observaram que, em 24 horas, com uma amamentação, houve acréscimo de $2.600 \%$ e com duas amamentações, houve acréscimo de $2.200 \%$ nas concentrações séricas de IgG dos bezerros neonatos.

Em outro trabalho de Erhard et al. (1999b), foi utilizado o teste de ELISA, que detectou as concentrações de IgG tanto no soro sangǘneo quanto no colostro, demonstrando ser um teste altamente eficiente na deteç̧ão e sensibilidade para diagnósticos de rotina, assim como foi observado neste trabalho.

Quanto às concentrações de IgG no colostro, obtidas em dois momentos diferentes, não apresentaram diferenças significativas ( $p>0,05$ ), porém, foi constatado, analisando-se por valores absolutos, que o colostro coletado mais tarde apresentou menores concentrações de IgG. Deste modo, foi verificado por Levieux e Ollier (1999) que, com o passar do tempo e o decorrer das ordenhas, mesmo ainda na fase de colostro, há uma queda abrupta nas concentrações de IgG, que chegaram a ser de $96,6 \%$ nos primeiros dias, em torno da oitava ordenha. Outros autores, como Sultan et al. (1993), também verificaram um decréscimo considerável de $70 \%$ entre as concentrações de IgG no colostro do primeiro para o segundo dia. 
Apesar de todos os autores consultados terem constatado uma diminuição na concentração de IgG, em amostras de colostro entre a primeira e a segunda ordentia ou em diferentes dias, neste trabalho foram colhidas amostras tanto do seio lactífero parte glandular (pré) quanto dos ductos lactíferos (pós), na mesma ordenha, não havendo, portanto, um padrão de diminuição de IgG $(p>0,05)$.

\section{Referências}

ARGENZIO, R. A. Introdução à função gastrintestinal. In: SWENSON, M. J. Dukes - Fisiologia dos animais domésticos. 10. ed. Rio de Janeiro: Guanabara Koogan, 1988. p. 229-242.

ERHARD, M. H.; GOBEL, E.; LEWAN, B.; LOSCH, U.; STANGASSINGER, $M$. Systemic availability of bovine immunoglobulin $G$ and chicken immunoglobulin $\mathrm{Y}$ after feeding colostrum and egg powder to newborn calves. Archives of Animal Nutrition, Berlin, v. 50, n. 4, p. 369-380, 1997.

ERHARD, M. H.; AMON, P.; YOUNAN, M.; ALI, Z.; STANGASSINGER, M. Absorption and synthesis of immunoglobulins $G$ in newborn calves. Reproduction in Domestic Animals, Berlin, v. 34, n. 3-4, p. 173-175, 1999 (a).

ERHARD, M. H.; AMON, P.; NUSKE, S.; STANGASSINGER, M. Studies on the systemic availability of maternal and endogenously produced immunoglobulin G1 and G2 in newborn calves by using newly developed ELISA systems. Journal of Animal Physiology and Animal Nutrition, Berlin, v. 81, n. 4-5, p. 239-248, 1999 (b).

FEITOSA, F. L. F.; BIRGEL, E. H.; MIRANDOLA, R. M. S.; PERRI, S. H. V. Diagnóstico de falha de transferência de imunidade passiva em bezerros através da determinação de proteína total e de suas frações eletroforéticas, imunoglobulinas $\mathrm{G}$ e $\mathrm{M}$ e da atividade da gama glutamil transferase no soro sangüíneo. Ciência Rural, Santa Maria, v. 31, n. 2, p. 251-255, 2001.

HADORN, U.; BLUM, J. W. Effects of feeding colostrum, glucose or water on the first day of life on plasma immunoglobulin $\mathrm{G}$ concentrations and gamma-glutamyltransferase activities in calves. Journal of Veterinary Medicine - Series A, Berlin, v. 44, n. 9-10, p. 531-537, 1997.

HOPKINS, B. A.; QUIGLEY, J. D. III. Effects of method of colostrum feeding and colostrum suplementation on concentrations of immunoglobulin $\mathrm{G}$ in the serum of neonatal calves. Journal of Dairy Science, Savoy, v. 80, n. 5, p. 979-983, 1997.

INTERNATIONALCOMMITTEE ON VETERINARYGROSSANATOMICAL NOMENCLATURE. Nomina anatômica veterinária, 4. ed. Zurich, 1994. p. 141.

JACOBSON, N. L.; McGILLIARD, A. D. Glândula mamária e lactação. In: SWENSON, M. J. Dukes - Fisiologia dos animais domésticos, 10. ed. Rio de Janeiro: Guanabara Koogan, 1988, p. 745-759.

LACETERA, N. Influence of high air temperatures on colostrum composition of dairy cows and passive imunization of calves. Zootecnica e Nutrizione Animale, Bologna, v. 24, n. 6, p. 239-246, 1997.

\section{Conclusões}

Bezerros que têm acesso ao colostro nas primeiras horas de vida apresentam maior capacidade imunológica.

A concentração de IgG não varia na primeira ordenha da glândula mamária, podendo então o bezerro, ingerir o colostro tanto antes quanto depois da primeira esgota, que não haverá alteração na concentração de lgG sérica.

LEVIEUX, D.; OLLIER, A. Bovine immunoglobulin G, beta-lactoglobulin, alpha-lactalbumin and serum albumin in colostrum and milk during the early post partum period. Journal of Dairy Research, Cambridge, v. 66, n. 3, p. 421-430, 1999.

McGUIRK, S. M. Colostrum: quality and quantity. Irish Veterinary Journal, Dublin, v. 52, n. 4, p. 205-206, 1999.

PANCHAL, K. M.; BHAYANI, D. M.; VYAS, Y, L. Anatomy of bovine udder and its defence mechanism. Indian Journal of Dairy and Biosciences, New Delhi, v. 9, p. 112-116; 1998.

QUIGLEY, J. D. III.; FIKE, D. L.; EGERTON, M. N.; DREWRY, J. J.; ARTHINGTON, J. D. Effects of a colostrum replacement product derived from serum on immunoglobulin $\mathrm{G}$ absortion by calves. Journal of Dairy Science, Savoy, v. 81, n. 7, p. 1936-1939, 1998.

RAJARAMAN, V.; NONNECKE, B. J.; HORST, R. L. Effects of replacement of native fat in colostrum and milk with coconut oil on fat-soluble vitamins in serum and immune function in calves. Journal of Dairy Science, Savoy, v. 80, n. 10, p. 2380-2390, 1997.

ROMDHANE, S.B.; KHIARI, D.; MAKRAM, J.; ROMDANE, M. N.; LOUZIR, H.; M'BAZAA, A. Estimation of colostral immunity transfer in newborn calves through determination of GGT and protein levels in serum. Revue de Médecine Vétérinaire, Toulouse, v. 148, n. 7, p. 627-632, 1997.

SILVA, D. A. O.; CABRAL, D. D.; BERNARDINA, B. L. D.; SOUZA, M. A.; MINEO, J. R. Detection of Toxoplasma gondii specific antibodies in dogs. A comparative study of immunoenzymatic, immunofluorescent and haemagglutination titers. Memórias do Instituto Oswaldo Cruz, Rio de Janeiro, v. 92, p. 785-789, 1997.

SULTAN, Z. A.; HAMED, M. K.; EL-BANNA, M. K. Immunoglobulin concentration in colostrum and blood serum with reference to growth and vitality of Friesian calves. Egyptian Journal of Animal Production, Cairo, v. 30, n. 2, p. 173-188, 1993.

VIEIRA, S. Introdução à Bioestatística. Rio de Janeiro: Campus, 1998. $197 \mathrm{p}$.

VIRTALA, A. M. K.; GROHN, Y. T.; MECHOR, G. D.; ERB, H. N. The effect of maternally derived immunoglobulin $\mathrm{G}$ on the risk of respiratory disease in heifers during the first 3 months of life. Preventive Veterinary Medicine, Amsterdam, v. 39, n. 1, p. 25-37, 1999.

WILSON, M. B.; NAKANE, P. K. Antibody conjugated to horse-hadish peroxidase. In: KANPP, W.; HOLUBAR, K.; WICK,G. Immunofluorescence and related staining technique. Elsevier North Holland Biomedical Press, Amsterdam, p. 215-224, 1978.

WITTUM, T. E.; PERINO, L. J. Passive immune status at postpartum hour 24 and long-term health and performance of calves. American Journal of Veterinary Research, Schaumburg, v. 56, n. 9, p. 1149-1154, 1995. 